\title{
Multi-heme cytochromes—new structures, new chemistry $\uparrow$
}

\author{
Christopher G. Mowat* and Stephen K. Chapman* \\ EaStCHEM, School of Chemistry, University of Edinburgh, West Mains Road, Edinburgh, \\ UKEH9 3JJ.E-mail: C.G.Mowat@ed.ac.uk,S.K.Chapman@ed.ac.uk.; Fax: 44131 650 6453; \\ Tel: 441316507544
}

Received 12th April 2005, Accepted 17th June 2005

First published as an Advance Article on the web 26th September 2005

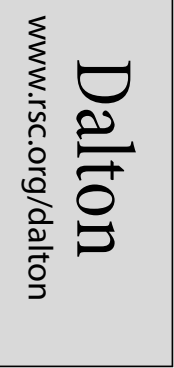

Heme is one of the most pervasive cofactors in nature and the c-type cytochromes represent one of the largest families of heme-containing proteins. Recent progress in bacterial genomic analysis has revealed a vast range of genes encoding novel c-type cytochromes that contain multiple numbers of heme cofactors. The genome sequence of Geobacter sulfurreducens, for example, includes some one hundred genes encoding c-type cytochromes, with around seventy of these containing two, or more, heme groups and with one protein containing an astonishing twenty seven heme groups. This wealth of cytochromes is of great significance in the respiratory flexibility shown by bacteria such as Geobacter. In addition, we are now discovering that many of these multi-heme cytochromes have associated enzymatic activities and in some cases this is revealing new chemistries. The purpose of this perspective is to describe recent progress in the structural and functional analyses of these new multi-heme cytochromes. To illustrate this we have chosen to focus on three of these cytochromes which exhibit catalytic activities; nitrite reductase, hydroxylamine oxidoreductase and tetrathionate reductase. In addition we consider the multi-heme cytochromes from Geobacter and Desulfovibrio species. Finally, we consider and contrast the repeating structural modules found in these multi-heme cytochromes.

$\dagger$ Based on the presentation given at Dalton Discussion No. 8, 7-9th September 2005, University of Nottingham, UK.

\section{Introduction}

The recent publication of the genome sequence of Geobacter sulfurreducens ${ }^{1}$ revealed that this organism contains 111 genes encoding c-type cytochromes (as defined by the presence of the c-type heme attachment motif). Of these, 73 were found to contain two or more heme groups, with one containing 27 heme groups. This extraordinary abundance of cytochromes helps the organism utilize a diverse range of respiratory pathways and terminal electron acceptors, including metal ions. As a comparison, the genome sequence of another metal ionreducing bacterium, Shewanella oneidensis, ${ }^{2}$ contains 39 genes encoding c-type cytochromes (14 of which contain 4 or more hemes). Although a relatively small number compared to $G$. sulfurreducens, this still represents the second largest number of c-type cytochromes found in any organism sequenced to date.

The presence of multi-heme cytochromes is also a feature of the sulfate- and sulfur-reducing bacteria such as Desulfovibrio and Desulfuromonas species. However, the use of multi-heme cytochromes is by no means limited to proteins involved only in electron transfer. There are well-studied families of multiheme cytochromes which are able to bind substrates at one of the heme groups and display enzymatic activity. In this article we will present a review of some of the most interesting and intriguing multi-heme cytochromes. In particular we will focus on two well-characterised enzyme systems, hydroxylamine oxidoreductase (HAO) from Nitrosomonas europaeae, and the cytochrome c nitrite reductase (NrfA). In addition, recent work carried out in our laboratory on a novel tetrathionate reductase from Shewanella oneidensis will be discussed, and for these three systems we will consider the nature of their differing and unusual active sites in terms of the chemistry occurring there.

Chris Mowat was born in Edinburgh in 1974. He obtained his B. Sc. from the University of Edinburgh in 1996 and his Ph.D. in enzymology from the same institution in 2000. He remains at the University of Edinburgh carrying out post-doctoral work with Professors Graeme Reid and Steve Chapman. His research is focussed upon the crystallographic study of multi-heme cytochromes from Shewanella and Geobacter.

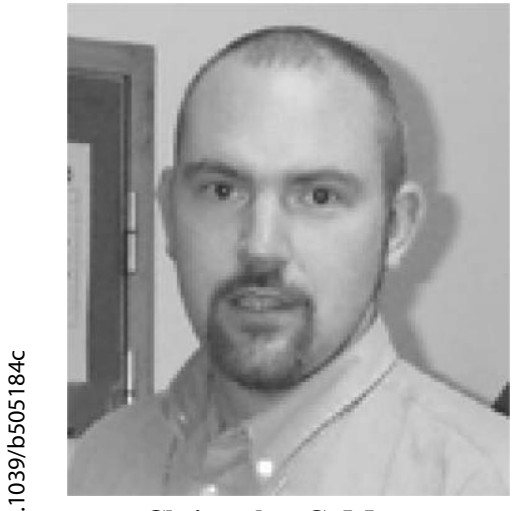

Christopher G. Mowat

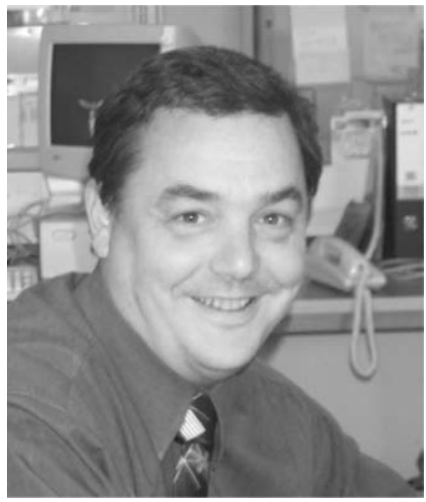

Stephen K. Chapman
Steve Chapman received his Ph.D. from the University of Newcastle in 1983. After a NATO fellowship at the Massachusetts Institute of Technology he returned to the UK to take up a lectureship at the University of Edinburgh. In 1996 he was appointed to a chair of Biological Inorganic Chemistry and in 2000 he became Head of School of Chemistry. His research interests include; metalloproteins, biological electron transfer, molecular enzymology and protein engineering. For more information on his research please visit his website at: http://www.chem.ed.ac.uk/chapman/ 
We will also discuss the nature of some of the multi-heme cytochromes produced by G. sulfurreducens, and provide an overview of the types of cytochromes utilised by sulfate-reducing microorganisms, perhaps the most extensively studied class to date. In doing so we aim to highlight the similarities between the arrangements of the hemes within these cytochromes, and the importance of this to their function.
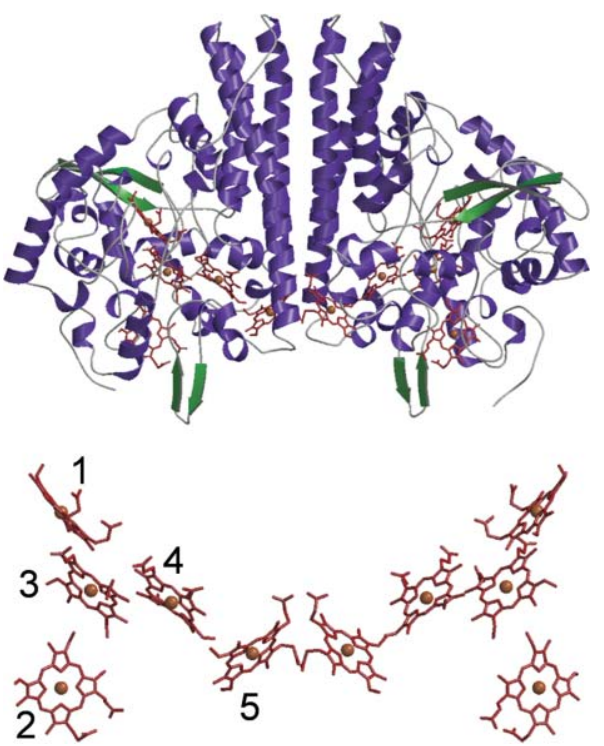

Fig. 1 (top) The structure of the dimeric cytochrome c nitrite reductase (NrfA) from Wolinella succinogenes [PDB ID 1FS7]. (bottom) The heme arrangement in the dimer. Heme 1 is the active-site heme in each monomer, and the close proximity of heme 5 from each subunit can be seen.

\section{The pentaheme cytochrome $\mathbf{c}$ nitrite reductase}

The biological nitrogen cycle involves a network of reactions catalysed by a number of different metalloenzymes. The process of dissimilatory nitrate ammonification covers redox transitions of nitrogen between the highest oxidation state $(+5$, nitrate) and the lowest $(-3$, ammonia). In this respiratory pathway the first step is reduction of nitrate to nitrite, with nitrite being the only intermediate released during the whole sequence of events. Subsequent conversion of nitrite to ammonia is accomplished in a six-electron reaction (1) catalyzed by cytochrome c nitrite reductase.

$$
\mathrm{NO}_{2}{ }^{-}+8 \mathrm{H}^{+}+6 \mathrm{e}^{-} \rightarrow \mathrm{NH}_{4}{ }^{+}+2 \mathrm{H}_{2} \mathrm{O}
$$

These enzymes are pentaheme cytochromes of $52-65 \mathrm{kDa}$ encoded by a single gene $(n r f A)$. The crystal structures of the enzymes from the sulfur-reducing bacterium Sulfurospirillum deleyianum, ${ }^{3}$ the rumen bacterium Wolinella succinogenes, ${ }^{4}$ and the enteric bacterium Escherichia coli $^{5}$ have been determined. All three structures reveal the enzyme to be a compact homodimer, indicating that these represent members of a family of homologous NrfA proteins, which are all presumed to be physiologically dimeric, and which all share important structural features. The structure of the Wolinella succinogenes enzyme is shown in Fig. 1, it is the highest resolution nitrite reductase structure available (1.6 $\AA$ ). The protein folds into one compact domain dominated by three long $\alpha$-helical segments, two of which are key elements in dimer formation through a predominantly hydrophobic surface. The five heme groups in each monomer are in close contact, with edge-to-edge distances between hemes as little as $4 \AA$. The heme arrangement in the dimer is shown in Fig. 1, and shows that within each monomer the hemes form both near-parallel and near-perpendicular arrangements. Hemes 1, 3 and 4 are arranged as a group of three which are essentially coplanar, while hemes 2 and 5 are further apart. Heme 2, which has been proposed as the entry point for electrons to the enzyme and is only $6.0 \AA$ from heme 3 and heme 5 is only $5.6 \AA$ from heme 4 . If we consider the dimer itself, then there is an intriguing arrangement between hemes 5 from either monomer. These hemes are only $5.9 \AA$ apart, leading to the suggestion of an electronic interaction between the monomers which may be functionally relevant. ${ }^{6}$ The reduction potentials of the hemes have been determined. ${ }^{7,8}$ Heme 1 is reduced together with heme 3 in a cooperative two-electron process with a potential of $-107 \mathrm{mV}$. Heme 2 has a potential of $-37 \mathrm{mV}$, while hemes 4 and 5 require much lower potentials, being reduced with a midpoint potential of around $-320 \mathrm{mV}$. The active site of the enzyme is located at heme 1 which displays an unusual lysinecoordination arising from the presence of a CXXCK motif in the protein sequence, resulting in an amine nitrogen as the proximal ligand (Lys134 in the W. succinogenes enzyme, Lys126 in the $E$. coli enzyme, Lys 133 in the $S$. deleyianum enzyme). The nature of the distal ligand to heme 1 varies in each structure, but has been observed as water/hydroxide (E. coli), sulfate ( $W$. succinogenes $/ S$. deleyianum) and azide ( $W$. succinogenes), the latter two being inhibitors of nitrite reductase. In addition, the $W$. succinogenes enzyme has been crystallised in the presence of nitrite and hydroxylamine, a putative reaction intermediate. ${ }^{9}$ Access to the active site has been demonstrated to be via two narrow channels from the protein surface. In contrast to the active-site heme, the remaining four hemes in each monomer are conventional c-type hemes, bound via typical $\mathrm{CXXCH}$ sequences and each bis-histidine-ligated.

A combination of structural analyses and density functional calculations has been used in an attempt to delineate the mechanism of the six-electron reduction of nitrite to ammonia. ${ }^{9}$ The reaction is initiated with the binding of nitrite to the reduced enzyme, and ammonia is produced without the release of intermediates such as NO or hydroxylamine. Indeed, although the enzyme is capable of reducing NO and hydroxylamine to ammonia, these reactions proceed with specific activities only $\sim 1 \%$ and $\sim 50 \%$ of the value for nitrite. ${ }^{10}$ In the proposed reaction mechanism, initial heterolytic cleavage of the first $\mathrm{N}-\mathrm{O}$ bond is followed by two one-electron reductions and a protonation step to yield $\mathrm{Fe}(\mathrm{II})-\mathrm{HNO}$. This species is further reduced by two electrons to give $\mathrm{Fe}(\mathrm{II})-\mathrm{H}_{2} \mathrm{NOH}$. Another oneelectron reduction leads to the release of water from this hydroxylamine intermediate, and the final reduction step is followed by ammonia dissociation. The key features of this mechanism are threefold. Firstly, the mechanism proceeds as a series of reduction and protonation steps. The effect of this is that with each reduction the affinity of the intermediate for protons is increased, and with each protonation the electrophilicity of the bound species is increased. This is necessary in order to reduce the nitrite double bond so that hydroxylamine can be formed and readily cleaved to produce ammonia. The reaction is driven by the thermodynamically favourable continuous supply of electrons. The second key aspect of the mechanism is the spin state of the heme-1 iron. The initial change from high spin to low spin that accompanies nitrite binding allows the whole reaction to proceed without further spin-state changes. Thirdly, the availability of the NO $\pi^{*}$-orbitals to accept two electrons significantly contributes to the activation of the second $\mathrm{N}-\mathrm{O}$ bond.

Although such a mechanism is certainly consistent with experimental observations, questions remain as to the significance and the role of the heme arrangement in electron delivery in the enzyme. It has been shown that the organisation of $n r f A$ gene clusters allows definition of two distinct groups. In one of these, which includes $W$. succinogenes and $S$. deleyianum, $n r f A$ clusters with $n r f H$, a gene encoding a membrane-anchored tetraheme cytochrome of the NapC quinol dehydrogenase family., ${ }^{4,11,12}$ Contrastingly, in the second group, which includes E. coli, $n r f A$ clusters with genes encoding $\mathrm{NrfB}$, a periplasmic pentaheme cytochrome, along with $\mathrm{NrfC}$ (a periplasmic $4 \times[4 \mathrm{Fe} 4 \mathrm{~S}]$ ferredoxin) and $\mathrm{NrfD}$ (a membrane-integral quinol dehydrogenase). 
From this information it seems clear that electron transfer from the quinone pool to nitrite reductase differs in the two groups.

In the case of the $W$. succinogenes and S. deleyianum systems, electrons are delivered to cytochrome c nitrite reductase via $\mathrm{NrfH} .{ }^{12}$ Indeed it has been demonstrated that in such organisms NrfA represents the soluble, catalytic subunit of a NrfHA nitrite reductase complex. Given that NrfA is believed to operate as a dimer, it is assumed that the physiological arrangement of NrfHA would be as an $\alpha_{2} \beta_{2}$ complex, although the structure of the NrfHA complex is as yet unavailable. ${ }^{13}$

For the group including E. coli, it has been demonstrated that $\mathrm{NrfB}$ exists as a homodimer of $\sim 40 \mathrm{kDa}$ molecular weight. ${ }^{14}$ Spectroscopic analysis indicates that all five ferric hemes are low-spin and most likely coordinated by two histidine residues. The ability of the reduced NrfB dimer to transfer electrons to the catalytically competent NrfA dimer has also been shown, and this implies the transient formation of a 20 -heme $[\mathrm{NrfB}]_{2}[\mathrm{NrfA}]_{2}$ complex during catalysis.

In discussing the pentaheme cytochrome c nitrite reductase and the relationship between structure and function in terms of its heme arrangement, it is interesting to note that the genome sequence of Geobacter sulfurreducens ${ }^{1}$ contains a gene encoding a $61 \mathrm{kDa}$ protein (GSU0357) which is annotated as a member of this family. What is remarkable about this protein is that although sequence homology with NrfA proteins points to such a role, this protein is an octaheme with seven typical $\mathrm{CXXCH}$ motifs and a further CXXCK motif. Clearly such a protein is an obvious target for study, and the apparent differences in heme content lead to questions as to whether it also functions as a dimer, and what the physiological redox partner may be.

\section{The octaheme hydroxylamine oxidoreductase}

In contrast to the dissimilatory nitrate ammonification respiratory processes described above, chemoautotrophic organisms obtain energy from the oxidation of inorganic substrates. However, whereas nitrate ammonification takes advantage of favourable electrochemical potentials for reduction of species in the pathway, the limited supply of inorganic materials with a suitably low reduction potential leads to slow growth of such organisms. For this reason chemoautotrophs have evolved adaptations to survive under such conditions. An example of such exists in the nitrifying chemoautotrophic bacterium Nitrosomonas europaea. The respiratory system in $N$. europaea comprises ammonia monooxygenase (AMO) ${ }^{15}$ hydroxylamine oxidoreductase (HAO), ${ }^{16}$ the electron transfer cytochromes $\mathrm{c}_{554}$ and $\mathrm{c}_{552}$, and cytochrome c oxidase. Hydroxylamine oxidoreductase, which catalyses the oxidation of hydroxylamine to nitrite, eqn. (2),

$$
\mathrm{NH}_{2} \mathrm{OH}+\mathrm{H}_{2} \mathrm{O} \rightarrow \mathrm{NO}_{2}^{-}+4 \mathrm{e}^{-}+5 \mathrm{H}^{+}
$$

is a key component in that energy generated by $\mathrm{HAO}$ (in the form of reducing power) is able to flow in either direction in the chain. In the 'forward' direction, energy is gained when electrons are passed on to the electron transport chain involving cytochrome $\mathrm{c}_{554}$, cytochrome $\mathrm{c}_{552}$ and cytochrome c oxidase. In 'reverse' operation the cycling energy of the system may be restored by reduction of AMO for the production of hydroxylamine, or by providing electrons for the ATP-dependent production of $\mathrm{NAD}(\mathrm{P}) \mathrm{H}$.

Hydroxylamine oxidoreductase is a protein of $67 \mathrm{kDa}$ molecular weight, which contains seven c-type heme groups and a further novel heme known as $\mathrm{P} 460 .{ }^{17}$ The $\mathrm{P} 460$ heme has been shown to bind $\mathrm{CO}$, implying that it is high-spin, five-coordinate, and therefore likely to be involved in catalysis, ${ }^{18}$ while the typical c-type hemes participate in transfer of electrons from the active site to the physiological acceptor, cytochrome $\mathrm{c}_{554}{ }^{19}$

The crystal structure of HAO has been solved to $2.8 \AA$ resolution. ${ }^{20}$ This structure reveals that $\mathrm{HAO}$ exists as a trimer as shown in Fig. 2. Each subunit is folded into two distinct domains (a third C-terminal domain of 47 residues is not observed in the electron density and is assumed to be flexible). Of these, the $\mathrm{N}$-terminal domain (residues 1-269) consists of a short twostranded $\beta$-sheet and $14 \alpha$-helices and contains five of the ctype hemes and the active-site heme P460. The central domain (residues 270-499) consists of ten $\alpha$-helices, including the long helices seen in Fig. 2, and binds hemes 7 and 8. The arrangement of the 24 hemes of HAO is of great interest. From Fig. 2 it can be seen that the hemes are located in the 'lower' half of the trimer. The three active-site P460 hemes are found above the plane of a ring consisting of eighteen c-type hemes (hemes 1 are not part of the ring). All of the c-type hemes are axiallyligated by two histidine residues, and their reduction potentials have been found (both experimentally $y^{21,22}$ and by calculation ${ }^{23}$ ) to lie within a range between $-412 \mathrm{mV}$ and $+288 \mathrm{mV}$ (vs. SHE). The five-coordinate high-spin $\mathrm{P} 460$ heme is found to have a potential of $-260 \mathrm{mV}$ at $\mathrm{pH}$ 7.0. As would seem natural from inspection of the heme arrangement, EPR studies suggest that the hemes interact strongly with one another. ${ }^{24}$ The hemes of each protomer may be considered to be divided into four clusters, and these are shown in Fig. 3. The active-site P460 belongs to a triple-heme cluster which also includes hemes 6 and 7 in a parallel stacking arrangement with their propionate moieties directed towards the solvent. The edge to edge distances between these hemes are $3.8 \AA$ (P460-heme 6 ) and $4.1 \AA$ (heme 6-heme 7). Hemes 3 and 5 belong to a double-heme cluster parallel to
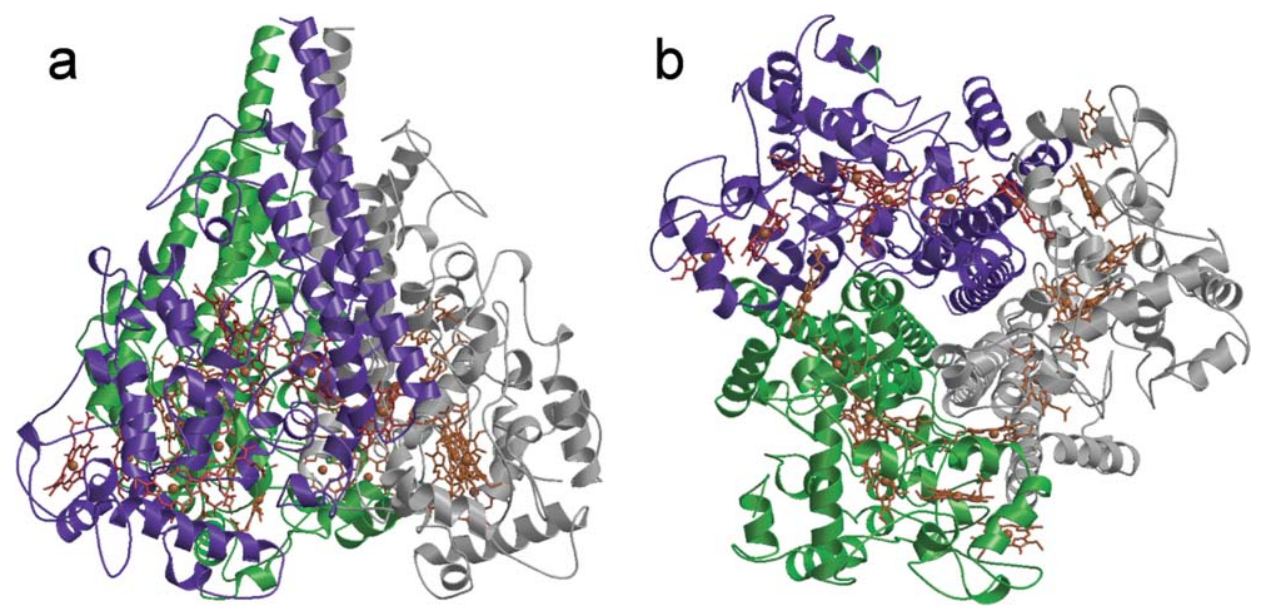

Fig. 2 The structure of hydroxylamine oxidoreductase from Nitrosomonas europaea [PDB ID 1FGJ]. Viewed side-on (panel a), the three subunits are coloured purple, green, and grey respectively. The location of the hemes at the base of the trimer can be seen. Panel (b) shows the view from the base of the trimer, with the 3 -fold symmetry obvious. 

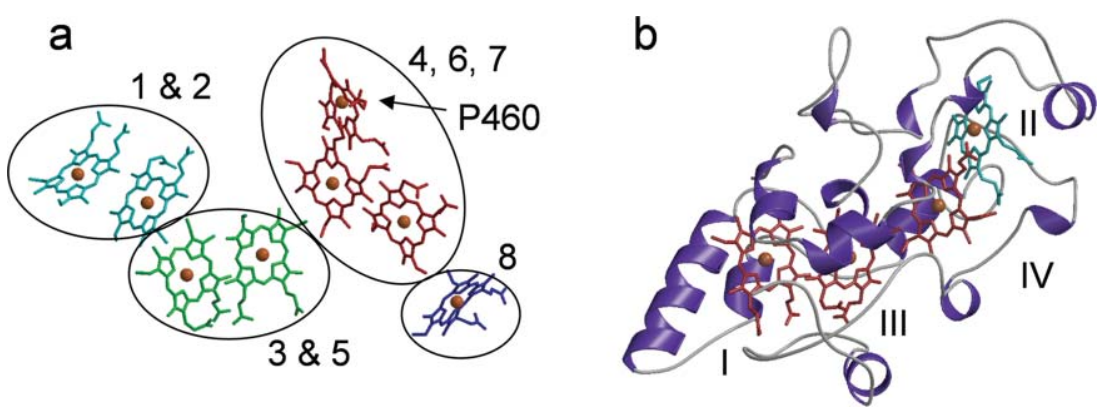

Fig. 3 (a) The arrangement of the hemes in one monomer of HAO. The clusters mentioned in the text are indicated by colour. (b) The structure of cytochrome $\mathrm{c}_{554}$ from $N$. europaea [PDB ID 1FT5]. The five-coordinate heme II is shown in cyan, and the similarity of the heme arrangement with hemes 3-6 of HAO can be seen by comparison with panel (a).

each other with an edge to edge distance of $3.9 \AA$, and heme 5 interacts with heme 6 of the triple-heme cluster. The third group is another double-heme cluster involving hemes 1 and 2, which are again essentially parallel, with a closest contact of $3.8 \AA$. Of these, heme 2 interacts with heme 3 in the other double-heme cluster. This second pair of hemes is also involved in trimer formation via hydrogen bonding with the adjacent subunit. This leaves heme 8 as the fourth 'cluster', close to heme 7 of the triple-heme cluster and to heme 2 of the adjacent subunit.

The active-site heme of HAO is basically the same as that seen for any other c-type heme, with attachment to the protein via a $\mathrm{CXXCH}$ binding motif. However, it is also found to be additionally covalently bound to the protein via Tyr467 from an adjacent subunit. It is likely that this crosslink is necessary for formation of the physiological trimer. Hydroxylamine has been shown to bind to $\mathrm{P} 460$ at the vacant sixth site, and various residues in the vicinity of the substrate binding site (such as Asp257, His268, Tyr334) have been proposed to be involved in catalysis. The process of nitrite formation from hydroxylamine requires two separate two-electron oxidations. Of the four electrons liberated, two are required for reduction of AMO (as mentioned above), and the remaining two are utilised for respiration. This two-step scheme results in HNO as the only enzyme-bound intermediate, and immediate oxidation of this species is necessary to prevent formation of $\mathrm{N}_{2} \mathrm{O}$ or nitric oxide rather than the desired product. It has been suggested that the enzyme is capable of achieving this by virtue of the nature of the P460 cofactor, which promotes the initial transfer of two electrons to hemes 6 and 7 . These electrons may then be rapidly transferred to the double-heme clusters more remote from the active site, thus leaving hemes 6 and 7 available to accept the second pair of electrons from P460. In this way the whole enzyme is able to readily transfer electrons as pairs. It is thought that heme 8 , which is located at the interface between the subunits, may function as means of directing residual electrons into the double heme ( 1 and 2 ) cluster belonging to the adjacent subunit.

Removal of electrons from $\mathrm{HAO}$ is carried out by cytochrome $\mathrm{c}_{554}$, and it is possible that these are taken via either of the doubleheme clusters identified. Formation of the HAO trimer results in a cavity which is a possible docking site for cytochrome $\mathrm{c}_{554}$. The tetraheme cytochrome $c_{554}$ displays no significant sequence homology to any other protein, and as such is considered to belong to its own class. ${ }^{25}$ The crystal structure of the protein has been solved, initially to $2.6 \AA$ resolution, ${ }^{26}$ but is now available to $1.6 \AA$ resolution ${ }^{27}$ and this is shown in Fig. 3. The four hemes are arranged in two pairs and are in fact essentially superposable with hemes 3-6 of HAO (heme 4 of HAO is the active-site P460). Three of the hemes of cytochrome $\mathrm{c}_{554}$ are found to be low-spin and axially-ligated by two histidine residues, while the other (heme II according to the appearance of the $\mathrm{CXXCH}$ motif in the protein sequence) is found to be ligated only by a single histidine ligand. Interestingly, when superposed with the HAO hemes, it is heme II which corresponds to the five-coordinate P460 in that protein. The measured reduction potentials of the cytochrome $\mathrm{c}_{554}$ hemes I to IV are $+47 \mathrm{mV},+47 \mathrm{mV},-147$ $\mathrm{mV}$ and $-276 \mathrm{mV}$ respectively. ${ }^{28,29}$ One of the high potential $(+47 \mathrm{mV})$ hemes is the high-spin heme II, while the unusual histidine-N $\delta$ ligation of heme $\mathrm{I}$ is thought to be responsible for its potential of $+47 \mathrm{mV}$. Heme to heme distances are similar to those observed for the structurally-equivalent hemes of HAO, with the parallel-stacked pairs having closest approach distances of 3.5-3.8 $\AA$, and the perpendicular central hemes (III and IV) are $6.0 \AA$ apart.

The presence of a five-coordinate heme in this protein naturally led to the question of whether it is capable of binding exogenous ligands, and indeed whether it displayed any catalytic activity. However, EPR studies have discounted this possibility and it would seem that the role of cytochrome $\mathrm{c}_{554}$ is solely that of electron transport. The proposal that the cavity formed by trimerisation in HAO could be involved in interaction with cytochrome $c_{554}$ is supported by the existence of a $30 \AA$ wide positively charged ridge on the surface of cytochrome $\mathrm{c}_{554}$. This ridge, above heme $\mathrm{I}$, is almost exactly the size of the negatively charged cavity in $\mathrm{HAO}$, and appears reasonable as a docking site. Such an interaction would leave the exposed edges of heme 1 in HAO and heme I in cytochrome $\mathrm{c}_{554}$ some $8 \AA$ apart, consistent with efficient electron transfer.

\section{The octaheme tetrathionate reductase}

As mentioned in the introduction, Shewanella oneidensis contains 39 genes which encode c-type cytochromes, a large proportion of which are multi-heme-containing. ${ }^{2}$ It is likely that this abundance of putative redox proteins is responsible for the ability of Shewanella species to utilise a wide range of terminal electron acceptors during anaerobic respiration. Such electron acceptors include metal ions such as Fe(III) and Mn(IV), nitrate and nitrite, sulfate and thiosulfate, and fumarate. Some of the multiheme cytochromes involved in the respiratory pathways which lead to these acceptors have been characterised to some degree. These include the periplasmic flavocytochrome c fumarate reductase $\mathrm{e}^{30-32}$ and the membrane-bound tetraheme CymA (a NapC/NirT homologue ${ }^{33}$ ), which has been shown to be involved in respiration with $\mathrm{Fe}(\mathrm{III})$, nitrate, fumarate, ${ }^{34}$ dimethyl sulfoxide and nitrite. ${ }^{35}$ Work has also been carried out on the outer membrane decaheme OmcA, which is thought to be involved in the reduction of insoluble $\mathrm{Fe}(\mathrm{III})$ species ${ }^{33}$ and the periplasmic decaheme MtrA which has been demonstrated to reduce soluble $\mathrm{Fe}(\mathrm{III})$ compounds. ${ }^{36}$ However, in addition to these proteins, a novel sequence was identified, with no known homologs, which contained eight $\mathrm{CXXCH}$ motifs. This octaheme protein of $\sim 50 \mathrm{kDa}$ molecular weight was isolated and the crystal structure solved to $2.2 \AA$ resolution. ${ }^{37}$ The protein was found to have a novel fold, with a mainly $\alpha$-helical $\mathrm{N}$-terminal region (residues 1 240) providing the framework for seven of the eight heme groups (hemes I-VII). The remainder of the protein (residues 241442 ) is mainly folded into a large $\beta$-sheet. The structure of the protein is shown in Fig. 4. Although the sequence would suggest 

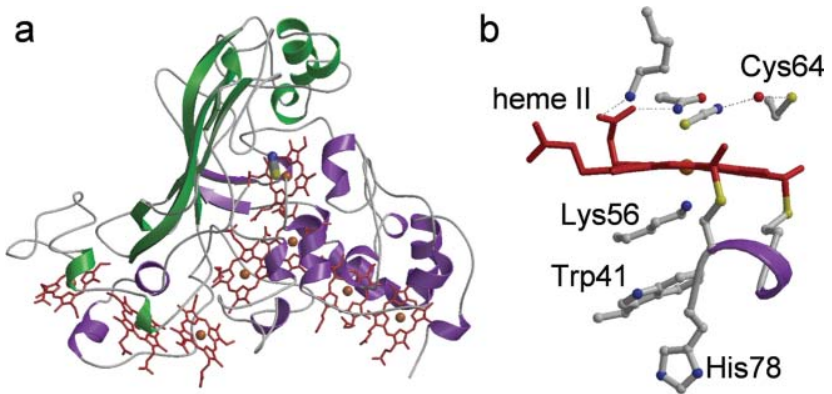

Fig. 4 (a) The structure of OTR from Shewanella oneidensis [PDB ID 1SP3]. The active-site heme can be seen in the centre of the molecule, with thiocyanate bound. (b) The active site of OTR. The unusual heme ligation is shown, with His 78 remote from the heme iron.

eight bis-histidine-ligated hemes, heme II was found to be fivecoordinate with a lysine residue (Lys56) as the axial ligand. This situation is analogous to the active-site heme in NrfA, which is the only other known example of this type of heme ligation. Remarkably however, while the lysine ligand in cytochrome c nitrite reductase is derived from a CXXCK heme binding motif, the $S$. oneidensis octaheme has no such sequence and the lysine is remote in the sequence from the heme-binding cysteine residues (Cys74 and Cys77). Furthermore His78, which is part of the heme II binding motif, is seen to be oriented away from the heme (Fig. 4), with a tryptophan residue (Trp41) between it and Lys56. This unprecedented heme ligation in the Shewanella octaheme raises the possibility that even in the designated NrfA from Campylobacter jejuni, which also has a $\mathrm{CXXCH}$ motif, ${ }^{38}$ the active-site could be ligated by a lysine. The sixth ligand to heme II in the octaheme structure is thiocyanate, due to the presence of $150 \mathrm{mM}$ potassium thiocyanate in the crystallisation solution.

Of the 17 cysteine residues in the protein sequence, 16 are involved in thioether linkages to the 8 heme groups. The remaining cysteine, Cys64, is located in what would appear to be a substrate binding pocket above heme II, some $7.5 \AA$ from the heme II iron. The structural evidence clearly implies an enzymatic role for the protein, and assays have been carried out to determine what the substrate might be. The enzyme was found to be able to catalyse the oxidation of thiosulfate under anaerobic conditions with the liberation of one electron from each thiosulfate consumed. Although thiosulfate may be oxidised further, to sulfite or sulfate, thus yielding more electrons per substrate molecule, this $1: 1$ stoichiometry suggests the formation of tetrathionate $\left(\mathrm{S}_{4} \mathrm{O}_{6}{ }^{2-}\right)$. As a result, the reverse reaction was assayed and found to be more efficient and the enzyme was therefore designated as an octaheme tetrathionate reductase (OTR), eqn. (3).

$$
\mathrm{S}_{4} \mathrm{O}_{6}{ }^{2-}+2 \mathrm{e}^{-} \rightarrow 2 \mathrm{~S}_{2} \mathrm{O}_{3}{ }^{2-}
$$

The only previously identified tetrathionate reductase is a membrane-bound molybdoenzyme from Salmonella typhimurium. ${ }^{39}$ In terms of a possible mechanism for tetrathionate reduction, it is possible that Cys64 may be involved in disulfide exchange, followed by a two-electron reduction via heme II. The reactivity of Cys 64 is supported by the apparent modification at the side chain sulfur atom of the residue in the structure, with electron density suggesting the possibility of a second bound sulfur or an oxygen atom. Unfortunately, these two possibilities are indistinguishable in the current structure. Cysteine modification to a sulfenic acid has been demonstrated as important in several enzymes ${ }^{40}$ while a persulfide derivative exists in the thiosulfate oxidising enzyme, SoxAX, from Rhodovulum sulfidophilum. ${ }^{41}$

The arrangement of the eight hemes in OTR is shown in Fig. 5. The active-site heme II forms part of a three-heme cluster with hemes IV and V. This cluster is almost identical to that observed for hemes 4 (the P460), 6 and 7 in hydroxylamine oxidoreductase. There are also two pairs of hemes in OTR (hemes I and III and hemes IV and V) which are organised in the same way as the two

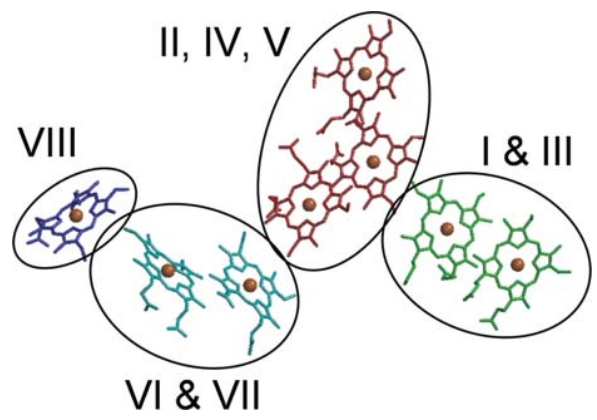

Fig. 5 The heme arrangement in OTR. Clusters of hemes similar to those described for HAO are indicated.

double heme clusters in HAO. In fact, it is possible to superpose 7 of the eight hemes in OTR and HAO, with heme VIII in OTR being equivalent to heme 8 in HAO. This superposition can be seen in Fig. 6, and it is notable that although the arrangement of the active-site triple heme cluster is identical in each enzyme, in order to achieve superposition of the remaining seven hemes the active-site hemes become resident on either side of the seven heme chain. It is also found that the five heme groups of cytochrome c nitrite reductase overlay with five of those in OTR (Fig. 6). Hemes I to V of NrfA are positionally related to hemes II to VI of OTR respectively. This structural fit extends even to the position of the substrate binding site and the activesite heme lysine ligand in either enzyme.
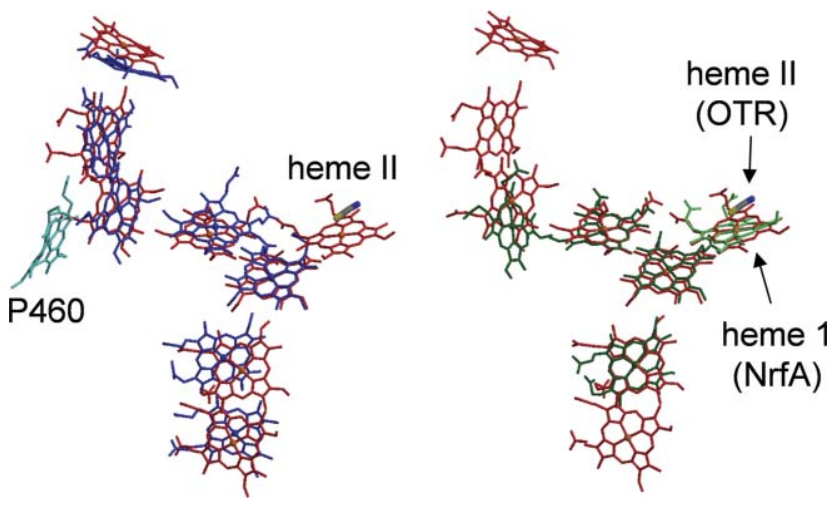

Fig. 6 Comparison of the heme arrangement in OTR (in red), with that in HAO (blue, left) and in NrfA (green, right).

Characterisation of OTR is at a much earlier stage than the extensively-studied HAO and NrfA, and as yet little is known about its mechanism and respiratory pathway. However, encoded on the same $S$. oneidensis operon as OTR is a monoheme cytochrome c which may be involved in electron transfer to OTR. At present this is purely speculative and it is possible that OTR is reduced by some other protein, such as CymA.

\section{Multi-heme cytochromes from Geobacter sulfurreducens}

Dissimilatory reduction of $\mathrm{Fe}(\mathrm{III})$ is likely to represent an early form of bacterial respiration, but it remains an important geochemical process in sedimentary environments. It has been demonstrated that in environments where $\mathrm{Fe}(\mathrm{III})$ is an important respiratory terminal electron acceptor, the microbial population is predominantly Geobacteraceae (a family of the $\delta$-proteobacteria). ${ }^{42}$ Studies on the mechanisms of electron transport within the Geobacteraceae have concentrated upon Desulfuromonas acetoxidans, ${ }^{43,44}$ Geobacter metallireducens, ${ }^{45}$ and Geobacter sulfurreducens, ${ }^{46,47}$ With the publication of the genome sequence of $G$. sulfurreducens, ${ }^{1}$ several multi-heme cytochromes have been identified as potentially interesting, and some of these are thought to be involved in $\mathrm{Fe}(\mathrm{III})$ reduction. One 
such protein is the periplasmic triheme cytochrome $\mathrm{c}_{7}(\mathrm{PpcA}){ }^{48}$ These small cytochromes represent the smallest members of the cytochrome $c_{3}$ superfamily, and crystal structures are available for the proteins from $D$. acetoxidans (also known as cytochrome $\left.\mathrm{c}_{551.5}\right)$ and $G$. sulfurreducens. ${ }^{49}$ The structure of PpcA from $G$. sulfurreducens is shown in Fig. 7. It has been demonstrated that PpcA is able to reduce metal ions including Fe(III), U(VI) and $\mathrm{Cr}(\mathrm{VI})$, and a chromate binding site has been proposed for the $D$. acetoxidans protein. ${ }^{50}$ Further to this, in the case of $D$. acetoxidans, a role has been proposed for the protein in sulfur reduction ${ }^{51}$ Indeed it has also been suggested that the protein may play a similar role to that carried out by cytochrome $c_{3}$ in sulfate-reducing bacteria, acting as a partner of the periplasmic hydrogenase. ${ }^{52}$ However, in addition to the direct reduction of soluble species which are able to enter the periplasm, the $G$. sulfurreducens protein is able to transfer electrons derived from acetate to a terminal $\mathrm{Fe}$ (III)-oxide reductase located on the outer membrane of the cell. ${ }^{53}$ As a consequence of these various abilities of cytochrome $c_{7}$, there remains considerable debate as to the precise physiological role of the protein. From the crystallographic and NMR studies it can be seen that cytochromes $\mathrm{c}_{7}$ are structurally similar to the tetraheme cytochromes $\mathrm{c}_{3}$ from the sulfate-reducing bacteria. There are, however, notable differences in that cytochromes $\mathrm{c}_{7}$ are considerably smaller (around 70 residues compared to around 120 in cytochromes $\mathrm{c}_{3}$ ), and that heme II (according to the cytochrome $\mathrm{c}_{3}$ nomenclature) and the region of polypeptide responsible for its binding are missing. As a result, the heme groups of PpcA and homologs are numbered I, III, and IV to facilitate easier comparison with the tetraheme proteins. Interestingly, although the sequence identity between the $G$. sulfurreducens and $D$. acetoxidans cytochrome $\mathrm{c}_{7}$ is $46 \%$, the level of structural homology is comparatively low, with an rms deviation of $\alpha$-carbons of $2.5 \AA .^{49}$ The three heme groups form the core of the protein (Fig. 7), with heme III located between heme I and heme IV (themselves related by a pseudo-two-fold symmetry axis). The distances between the hemes are short, with hemes I and III in van der Waals contact with each other and heme IV in van der Waals contact with one of the histidine ligands to heme III. Comparing the two available cytochrome $c_{7}$ structures, the major difference is the region around heme I, with this heme assuming markedly distinct orientations in the two proteins. This is due to the fact that there are amino-acid insertions before and after the $\mathrm{CXXCH}$ binding motif for heme I in the G. sulfurreducens sequence. However, although this peculiarity leads to significant differences in the iron-to-iron distances involving heme I in the two proteins, the closest edge-to-edge distances (those important for consideration of electron transfer properties) are the same in both. Further characterisation of the redox properties of $G$. sulfurreducens PpcA has been carried out. ${ }^{54}$ This work focussed on the role of a conserved phenylalanine residue (Phe15 in the G. sulfurreducens protein) which is present in both proteins mentioned here, as well as in the four homologs of PpcA in $G$. sulfurreducens and in the tetraheme cytochromes $\mathrm{c}_{3}$. This residue forms a structural motif involving hemes I and III. The redox
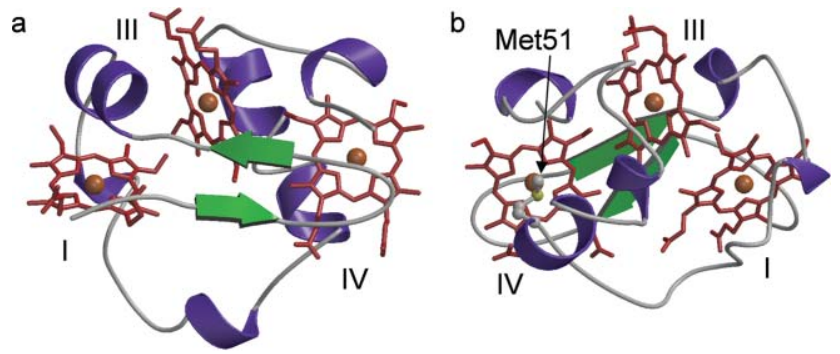

Fig. 7 (a) The structure of cytochrome $\mathrm{c}_{7}(\mathrm{PpcA})$ from Geobacter sulfurreducens [PDB ID 1OS6]. (b) The structure of the cytochrome $\mathrm{c}_{7}$-like domain C of the dodecaheme protein GSU1996 [PDB ID 1RWJ]. The methionine ligand to heme IV is shown. potentials of the cytochrome $\mathrm{c}_{7}$ hemes are found to lie within a $100 \mathrm{mV}$ range, with the highest potential heme around -100 $\mathrm{mV}$ and the lowest around $-200 \mathrm{mV}$. Substitution of Phe15, in PpcA, to tyrosine or tryptophan reveals that this residue helps to modulate the heme reduction potentials, a role that is clearly important for physiological function. Interestingly, the redox behaviour of PpcA and the D. acetoxidans protein is found to differ in that PpcA displays a $\mathrm{pH}$ dependence of reduction potentials which is absent in the Desulfuromonas cytochrome. This result is taken as an example of how structurally related proteins display functional differences thus leading to varying physiological roles. In the case of both available structures, the crystal packing has been found to result in close interaction of the hemes of adjacent molecules. For the D. acetoxidans protein this results in the close proximity of heme I and heme IV of symmetry-related molecules. Further to this, heme IV of one molecule and heme III of its neighbour are almost parallel to one another, in an orientation which is often observed in electron transport proteins. ${ }^{26}$ This packing has led to the hypothesis that such interaction between the cytochrome $\mathrm{c}_{7}$ molecules could form the basis of an intermolecular electron transfer pathway. ${ }^{44}$ In the G. sulfurreducens PpcA similar close packing leads to close intermolecular heme-heme distances, with the closest approach being only 7.0 Å between the porphyrin rings of hemes I and IV on adjacent molecules (intramolecular heme-heme distances are only $\sim 1 \AA$ shorter than this). This leads to a one-dimensional array of PpcA molecules with $\mathrm{N}$ - and $\mathrm{C}$-termini arranged so that it is possible to envisage a continuous polypeptide. Such a finding raises implications as to the possible arrangement of some other G. sulfurreducens multi-heme cytochromes. In the genome of the bacterium there are also found three cytochromes which appear to be polymers of $\mathrm{c}_{7}$-type domains (two tetramers containing twelve hemes each, and one nonamer containing 27 hemes). One of these dodecaheme cytochromes (GSU1996) has been cloned as four individual domains (A to D), and domain $\mathrm{C}$ has been crystallised and the structure published ${ }^{55}$ From this structure it can be seen that whereas in the two cytochrome $\mathrm{c}_{7}$ structures mentioned previously all hemes are ligated by two histidine residues, in domain $\mathrm{C}$ heme IV is ligated by one histidine and one methionine. This is shown in Fig. 7. Consistent with the presence of a methionine heme ligand, the potential of domain $\mathrm{C}$ is found to be increased by $50 \mathrm{mV}$ relative to that of PpcA (domain $\mathrm{C}$ midpoint potential $=-105 \mathrm{mV}$, PpcA midpoint potential $=$ $-155 \mathrm{mV}$ ). It is interesting to note that sequence comparison between domains of these polymeric proteins indicates that the methionine ligand is conserved in all, leading to questions as to the functional significance of such architecture. Intriguingly, although the crystal packing of PpcA was taken as evidence for the possible linear arrangement of such domains in the larger 'polymeric' cytochromes, the packing observed for domain $\mathrm{C}$ is such that the $\mathrm{N}$ - and $\mathrm{C}$-terminii cannot be connected, although the hemes of neighbouring molecules remain very close ( $\sim 4.0 \AA$ ) $)$. Perhaps it is not surprising that in proteins with such a low amino-acid : heme ratio crystal packing would lead to close approach of the hemes, and any apparently polymeric arrangement may be coincidental. However, recent work on the expression of hexaheme fragments of the same protein (the product of ORF GSU1996) has led to the preliminary crystal structure of the C and D domains together. ${ }^{56}$ For this 'dimer' structure at least it would appear that the hemes adopt an essentially linear pattern in a similar manner to that proposed for PpcA.

Although, as yet, much of the work on Geobacter multi-heme cytochromes has been focussed upon those mentioned above, there are clear targets for study, including homologs of other proteins mentioned in this perspective. These include the $61 \mathrm{kDa}$ octaheme cytochrome c nitrite reductase homolog (GSU0357) mentioned previously, as well as homologs of the Shewanella octaheme tetrathionate reductase. From sequence comparison with OTR, one of these (GSU2201) would seem to have a 
methionine ligand to heme II in place of lysine (if the activesite heme ligation characteristics of OTR are conserved). Such a change would be likely to have considerable consequences for the properties of this heme, and it will be interesting to characterise such a seemingly unusual protein.

\section{Multi-heme cytochromes of the Desulfovibrio species}

The sulfate reducers are a group of microorganisms which derive energy from the anaerobic respiration of sulfate. Of the multi-heme cytochromes found in such organisms, the best characterised is the tetraheme cytochrome $c_{3}$ from the genus Desulfovibrio, of which there are several structures available from various strains..$^{57-61}$ The structure of the protein from $D$. gigas is shown in Fig. 8. The heme arrangement is similar to that described for the cytochromes $\mathrm{c}_{7}$, with the addition of heme II, and all hemes are characteristically low-potential ( -400 $\mathrm{mV}$ to $-165 \mathrm{mV}^{62}$ ) and bis-histidine-ligated. In Desulfovibrio species cytochrome $c_{3}$ has been demonstrated to be the most abundant periplasmic cytochrome, ${ }^{63}$ and is generally regarded to be the primary electron acceptor from periplasmic hydrogenase ${ }^{64}$ as well as a 'proton thruster', but the advent of the genome sequence of Desulfovibrio vulgaris Hildenborough ${ }^{65}$ has revealed that there are other tetraheme cytochromes $\mathrm{c}_{3}$ produced by the organism. In addition to these tetrahemes, other multi-heme proteins have been characterised. One of these is the $26 \mathrm{kDa}$ octaheme cytochrome $c_{3}$ (also known as cytochrome $\mathrm{cc}_{3}$ ) from D. desulfuricans Norway ${ }^{66}$ for which the crystal structure has been solved ${ }^{67}$ This octaheme is designated a cytochrome $c_{3}$ due to the fact that it is actually a dimer of two tetraheme $c_{3}$ units, and the protein is a redox partner of the [NiSeFe] hydrogenase. ${ }^{68}$ The structure of the protein is shown in Fig. 9, and from this it can be seen that the dimer interface is formed in the region close to heme 1 of each subunit, so that the distance between the two hemes 1 is only $\sim 5 \AA$. Another feature of the structure is the close contact of the sulfur atoms of Cys 38 in each subunit $(3.8 \AA$, close to van der Waals contact). These cysteine residues are involved in the $\mathrm{CXXCH}$ motif responsible for heme 1 binding, and such close interaction is proposed to be important for inter-subunit electron transfer. This arrangement is analogous to that found in the $29 \mathrm{kDa}$ dimeric cytochrome $\mathrm{c}_{3}$ from Desulfovibrio gigas, although in this protein the monomers are linked by two intersubunit disulfide bridges formed between Cys 5 and Cys 46 from each monomer. ${ }^{69}$

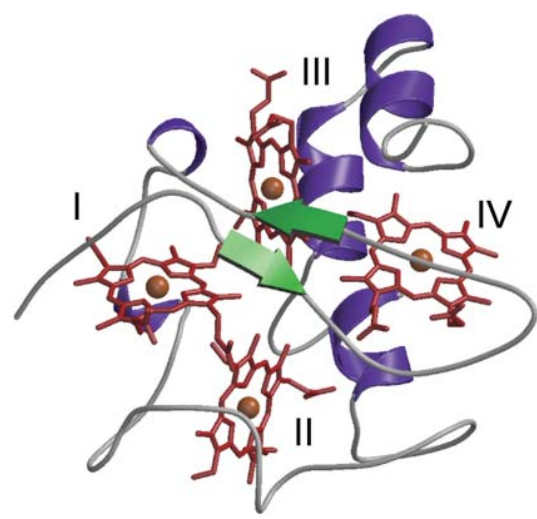

Fig. 8 Cytochrome $c_{3}$ from Desulfovibrio gigas [PDB ID 1WAD]. The structural similarity to cytochrome $\mathrm{c}_{7}$ is evident, with the obvious exception of the presence of heme II.

In addition to the small tetraheme $\mathrm{c}_{3}$ (either monomeric or dimeric), Desulfovibrio species also produce higher molecular weight cytochromes. One of these is the $37 \mathrm{kDa}$ nonaheme cytochrome c (9HcA) from $D$. desulfuricans ATCC $27774 .{ }^{70}$ The structure of the protein has been solved and found to consist of a fold similar to two fused tetraheme $c_{3}$ clusters with the other heme located asymmetrically between these two domains.

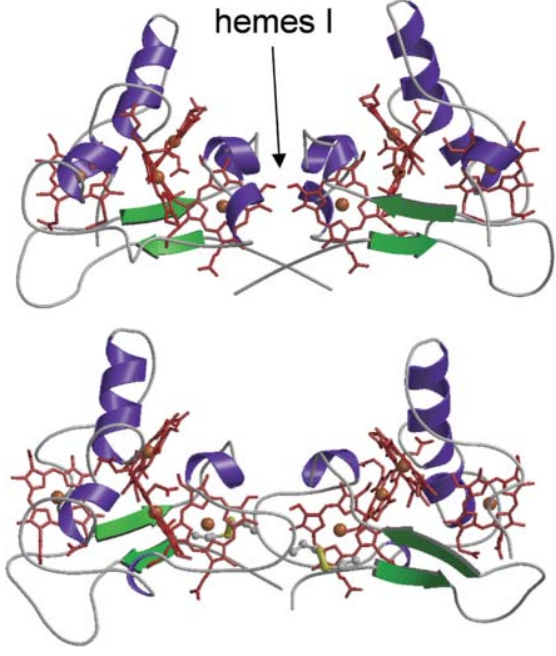

Fig. 9 (Top) The $26 \mathrm{kDa}$ dimeric cytochrome $\mathrm{c}_{3}$ from Desulfovibrio desulfuricans Norway [PDB ID 1CZJ], and (bottom) the $29 \mathrm{kDa}$ dimeric cytochrome $\mathrm{c}_{3}$ from D. gigas [PDB ID 1GYO]. In the bottom panel the inter-subunit disulfide bonds between Cys5 and Cys46 of either monomer are shown.

This is shown in Fig. 10. The hemes in the N-terminal $c_{3}$-like domain are numbered $1,2,3$ and 5 in terms of the location of their attachment motifs in the primary structure, and those in the C-terminal $c_{3}$-like domain are numbered $6,7,8$ and 9. Heme 4 lies in the interface between these domains. These sets of four hemes are the structural equivalents of hemes 1 to 4 in cytochrome $c_{3}$, so while the C-terminal domain appears a normal $\mathrm{c}_{3}$-like domain, the location of heme 4 in $9 \mathrm{HcA}$ arises from a loop insertion between the binding regions for hemes 3 and 5 . It is proposed that the role of heme 4 is as a bridge between the tetraheme clusters to facilitate electron transfer within the molecule. ${ }^{71}$ In addition, thermodynamic calculations
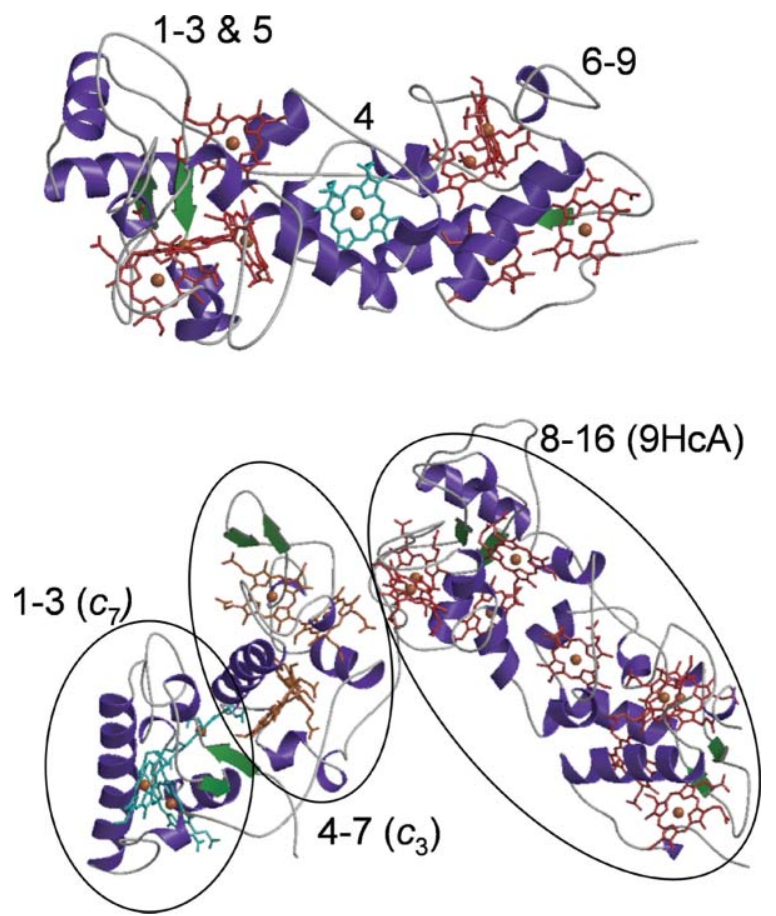

Fig. 10 The top panel shows 9HcA from Desulfovibrio desulfuricans [PDB ID 19HC]. Heme 4 is shown in cyan, and is located asymmetrically between two tetraheme cytochrome $c_{3}$-like domains. The lower panel shows HmcA from D. vulgaris [PDB ID 1H29]. The modular arrangement of this protein is highlighted, with the triheme $c_{7}$-like domain shown with cyan hemes $(1-3)$, the tetraheme $c_{3}$ domain shown with orange hemes (4-7), and the $9 \mathrm{HcA}$ domain shown with red hemes (8-16). 
provide evidence that the $\mathrm{N}$ - and $\mathrm{C}$-terminal domains function independently, with the reduction potentials of hemes 1 to 5 being lower (in the region of $-280 \mathrm{mV}$ to $-365 \mathrm{mV}$ ) than those of the C-terminal hemes (around $-255 \mathrm{mV}$ to $-285 \mathrm{mV}$ ). Heme 9 , however, is also found to have a particularly low potential ( $-305 \mathrm{mV}$ to $-345 \mathrm{mV}$ depending on the calculation used) and it has been suggested that electrons flow from the N-terminal domain through to the C-terminal domain, with heme 9 being the point of exit to other proteins in the pathway. ${ }^{72}$ The protein is encoded on an operon which also encodes three other proteins $(9 \mathrm{HcB}, 9 \mathrm{HcC}$ and $9 \mathrm{HcD})$ and these four proteins (the nonaheme, an iron-sulfur protein, a trans-membrane diheme cytochrome $b$ and another hydrophobic protein) are believed to form a redox complex involved in sulfate respiration..$^{73}$ In carrying out such a role, the nonaheme cytochrome $\mathrm{c}$ has been shown to accept electrons from hydrogenase via the tetraheme $c_{3}$ (and directly from hydrogenase). ${ }^{74}$

A similar role in coupling periplasmic hydrogen oxidation to cytoplasmic sulfate reduction in Desulfovibrio species has been proposed for the $\sim 65 \mathrm{kDa}$ hexadecaheme cytochrome $\mathrm{c}$, HmcA. The crystal structures of this protein from D. vulgaris Hildenborough and D. gigas have been solved. ${ }^{75-77}$ It can be seen from Fig. 10 that while HmcA may be described as composed of four cytochrome $\mathrm{c}_{3}$-like domains, it is perhaps more appropriate to state that there is a triheme cytochrome $\mathrm{c}_{7}$-like domain, a standard tetraheme cytochrome $\mathrm{c}_{3}$ domain, and a nonaheme 9HcA-like domain. Interestingly, heme 15 (part of the C-terminal module of the nonaheme domain) is found to be five-coordinate and high-spin with a single histidine ligand, but the heme iron is also within van der Waals contact with the side chain of an isoleucine residue. This occupation of what may have been thought to be a possible substrate binding site would require some conformational change to allow enzymatic activity, but no such activity or alternative structure has been observed. ${ }^{78}$ The gene for HmcA is part of a large operon encoding a putative six membered membranebound redox complex. The other members of the complex $(\mathrm{HmcB}-\mathrm{HmcF})$ include iron-sulfur proteins and membraneintegral proteins (including b-type cytochromes), and as with the $9 \mathrm{Hc}$ complex mentioned above, this complex is responsible for passing reducing equivalents from hydrogenase to the cytoplasm for sulfate reduction. The question of why $\mathrm{HmcA}$ requires so many hemes has also been addressed, especially when a similar function has been proposed for the smaller 9HcA. Indeed, comparison of the operons encoding these two multi-heme cytochromes reveals the greater intricacy (and therefore energy investment by the cell) of the Hmc complex. The nature of some of the proteins involved has led to the proposal that the complex may be bifunctional, with the different regions of $\mathrm{HmcA}$ interacting with different partner proteins. Whatever the precise physiological function (or functions), it is clear that the multi-heme cytochromes of the sulfate reducers are involved in elaborate respiratory pathways, with the possibility of multiple types of interaction all accomplished using a variation on the tetraheme arrangement of cytochrome $\mathrm{c}_{3}$.

\section{Structural modules in multi-heme cytochromes}

It should have become clear from this discussion of the structures and roles of various multi-heme cytochromes, that there is a high level of conservation of heme arrangement throughout. In the case of those proteins from the sulfate-reducing microorganisms such a phenomenon is perhaps unsurprising, given that they are all derived from variations of the tetraheme cytochrome $c_{3}$ module. However, in the case of the pentaheme cytochrome c nitrite reductase, and the octahemic hydroxylamine oxidoreductase and tetrathionate reductase there is no clear global structural (or sequence) similarity between any of these enzymes. Further to this it would appear, given the multiple possibilities that exist for overlaying subsets of hemes from these proteins, that there are conserved structural modules for arrangement of the hemes. The close-packing of hemes to form arrangements of near-parallel and near-perpendicular pairs (this grouping, known as the 'diheme elbow motif' is observed in every protein mentioned in this article) is seen in these three enzymes, along with cytochrome $\mathrm{c}_{554}$ from Nitrosomonas europaea, the flavocytochrome c fumarate reductases from Shewanella species $^{30-32}$ and others. It is possible that electron transfer between hemes is facilitated by the use of such heme packing motifs. ${ }^{26}$ It is also interesting to note that multi-heme cytochromes with such heme arrangements are produced by organisms that utilise nitrogen or sulfur containing compounds as an energy source. Consequently they may require such complexity as a means of carrying out the multi-electron redox chemistry that such metabolic processes involve. It is possible that such heme arrangements maximise the likelihood of productive electron transfer by placing many possible redox partners in the vicinity of one another, a process termed 'electron harvesting' ${ }^{79}$ In the future, Geobacter sulfurreducens, with its prodigious number of genes encoding multi-heme cytochromes, will surely yield more beautiful proteins (perhaps with novel enzymatic activities), and enable our further understanding of why such elaborate architectures are necessary.

All crystallographic figures were generated using BOBSCRIPT $^{80}$ and Raster 3D. ${ }^{81}$

\section{Acknowledgements}

The authors wish to acknowledge the United Kingdom Biotechnology and Biological Sciences Research Council (BBSRC) for funding (for C.G.M.).

\section{References}

1 B. A. Methé, K. E. Nelson, J. A. Eisen, I. T. Paulsen, W. Nelson, J. F. Heidelberg, D. Wu, N. Ward, M. J. Beanan, R. J. Dodson, R. Madupu, L. M. Brinkac, S. C. Daugherty, R. T. DeBoy, A. S. Durkin, M. Gwinn, J. F. Kolonay, S. A. Sullivan, D. H. Haft, J. Selengut, T. M. Davidsen, N. Zafar, O. White, B. Tran, C. Romero, H. A. Forberger, J. Weidman, H. Khouri, T. V. Feldblyum, T. R. Utterback, S. E. Van Aken, D. R. Lovley and C. M. Fraser, Science, 2003, 302, 1967-1969. 2 J. F. Heidelberg, I. T. Paulsen, K. E. Nelson, E. J. Gaidos, W. C. Nelson, T. D. Read, J. A. Eisen, R. Seshadri, N. Ward, B. Methé, R. A. Clayton, T. Mayer, A. Tsapin, J. Scott, M. Beanan, L. Brinkac, S. Daugherty, R. T. DeBoy, R. J. Dodson, A. S. Durkin, D. H. Haft, J. F. Kolonay, R. Madupu, J. D. Peterson, L. A. Umayan, O. White, A. M Wolf, J. Vamathevan, J. Weidman, M. Impraim, K. Lee, K. Berry, C. Lee, J. Mueller, H. Khouri, J. Gill, T. R. Utterback, L. A. McDonald, T. V. Feldblyum, H. O. Smith, J. C. Venter, K. H. Nealson and C. M. Fraser, Nat. Biotechnol., 2002, 20, 1118-1123.

3 O. Einsle, A. Messerschmidt, P. Stach, G. P. Bourenkov, H. D. Bartunik, R. Huber and P. M. H. Kroneck, Nature, 1999, 400, 476480.

4 O. Einsle, P. Stach, A. Messerschmidt, J. Simon, A. Kröger, R. Huber and P. M. H. Kroneck, J. Biol. Chem., 2000, 275, 39608-39616.

5 V. A. Bamford, H. C. Angove, H. E. Seward, A. J. Thomson, J. A. Cole, J. N. Butt, A. M. Hemmings and D. J. Richardson, Biochemistry, 2002, 41, 2921-2931.

6 W. Schumacher, U. Hole and P. M. H. Kroneck, Biochem. Biophys. Res. Commun., 1994, 205, 911-916.

7 H. C. Angove, J. A. Cole, D. J. Richardson and J. N. Butt, J. Biol. Chem., 2002, 277, 23374-23381.

8 J. D. Gwyer, H. C. Angove, D. J. Richardson and J. N. Butt, Bioelectrochemistry, 2004, 63, 43-47.

9 O. Einsle, A. Messerschmidt, R. Huber, P. M. H. Kroneck and F. Neese, J. Am. Chem. Soc., 2002, 124, 11737-11745.

10 P. Stach, O. Einsle, W. Schumacher, E. Kurun and P. M. H. Kroneck, J. Inorg. Biochem., 2000, 79, 381-385.

11 M. D. Roldán, H. J. Sears, M. R. Cheesman, S. J. Ferguson, A. J. Thomson, B. C. Berks and D. J. Richardson, J. Biol. Chem., 1998, 273, 28785-28790.

12 J. Simon, R. Gross, O. Einsle, P. M. H. Kroneck, A. Kröger and O. Klimmek, Mol. Microbiol., 2000, 35, 686-696.

13 O. Einsle, P. Stach, A. Messerschmidt, O. Klimmek, J. Simon, A. Kröger and P. M. H. Kroneck, Acta Crystallogr., Sect. D, 2002, 58 , 341-342. 
14 T. A. Clarke, V. Dennison, H. E. Seward, B. Burlat, J. A. Cole, A. M. Hemmings and D. J. Richardson, J. Biol. Chem., 2004, 279, 4133341339.

15 T. C. Hollocher, M. E. Tate and D. J. D. Nicholas, J. Biol. Chem., 1981, 256, 10834-10836.

16 A. B. Hooper and A. Nason, J. Biol. Chem., 1965, 240, 4044-4057.

17 K. K. Anderson, T. A. Kent, J. D. Lipscomb, A. B. Hooper and E. Munck, J. Biol. Chem., 1984, 259, 6833-6840.

18 A. B. Hooper, P. Debey, K. K. Anderson and C. Balny, Eur. J. Biochem., 1983, 134, 83-87.

19 D. M. Arciero, C. Balny and A. B. Hooper, Biochemistry, 1991, 30, 11466-11472.

20 N. Igarashi, H. Moriyama, T. Fujiwara, Y. Fukumori and N. Tanaka, Nat. Struct. Biol., 1997, 4, 276-284.

21 R. C. Prince, C. Larroque and A. B. Hooper, FEBS Lett., 1983, 163, 25-27.

22 M. J. Collins, D. M. Arciero and A. B. Hooper, J. Biol. Chem., 1993, 268, 14655-14662.

23 I. V. Kurnikov, M. A. Ratner and A. A. Pacheco, Biochemistry, 2005, 44, 1856-1863.

24 M. P. Hendrich, D. Petasis, D. M. Arciero and A. B. Hooper, J. Am. Chem. Soc., 2001, 123, 2997-3005.

25 D. J. Bergmann, D. M. Arciero and A. B. Hooper, J. Bacteriol., 1994, 176, 3148-3153.

26 T. M. Iverson, D. M. Arciero, B. T. Hsu, M. S. P. Logan, A. B. Hooper and D. C. Rees, Nat. Struct. Biol., 1998, 5, 1005-1012.

27 T. M. Iverson, D. M. Arciero, A. B. Hooper and D. C. Rees, J. Biol. Inorg. Chem., 2001, 6, 390-397.

28 D. M. Arciero, M. J. Collins, J. Haladjian, P. Bianco and A. B. Hooper, Biochemistry, 1991, 30, 11459-11465.

29 A. K. Upadhyay, D. T. Petasis, D. M. Arciero, A. B. Hooper and M. P. Hendrich, J. Am. Chem. Soc., 2003, 125, 1738-1747.

30 V. Bamford, P. S. Dobbin, D. J. Richardson and A. M. Hemmings, Nat. Struct. Biol., 1999, 6, 1104-1107.

31 P. Taylor, S. L. Pealing, G. A. Reid, S. K. Chapman and M. D. Walkinshaw, Nat. Struct. Biol., 1999, 6, 1108-1112.

32 D. Leys, A. S. Tsapin, K. H. Nealson, T. E. Meyer, M. A. Cusanovich and J. J. Van Beeumen, Nat. Struct. Biol., 1999, 6, 1113-1117.

33 S. J. Field, P. S. Dobbin, M. R. Cheesman, N. J. Watmough, A. J. Thomson and D. J. Richardson, J. Biol. Chem., 2000, 275, 8515-8522.

34 C. R. Myers and J. M. Myers, J. Bacteriol., 1997, 179, 1143-1152.

35 C. Schwalb, S. K. Chapman and G. A. Reid, Biochemistry, 2003, 42, 9491-9497.

36 K. E. Pitts, P. S. Dobbin, F. Reyes-Ramirez, A. J. Thomson, D. J. Richardson and H. E. Seward, J. Biol. Chem., 2003, 278, 2775827765.

37 C. G. Mowat, E. Rothery, C. S. Miles, L. McIver, M. K. Doherty, K. Drewette, P. Taylor, M. D. Walkinshaw, S. K. Chapman and G. A. Reid, Nat. Struct. Mol. Biol., 2004, 11, 1023-1024.

38 J. Simon, FEMS Microbiol. Rev., 2002, 26, 285-309.

39 M. Hensel, A. P. Hinsley, T. Nikolaus, G. Sawers and B. C. Berks, Mol. Microbiol., 1999, 32, 275-287.

40 A. Claiborne, T. C. Mallett, J. I. Yeh, J. Luba and D. Parsonage, $A d v$. Protein Chem., 2001, 58, 215-276.

41 V. A. Bamford, S. Bruno, T. Rasmussen, C. Appia-Ayme, M. R. Cheesman, B. C. Berks and A. M. Hemmings, EMBO J., 2002, 21 , 5599-5610.

42 D. R. Lovley, in Environmental Microbe-Metal Interactions, ed. D. R. Lovley, ASM Press, Washington, DC, 2002, pp. 3-30.

43 L. Banci, I. Bertini, M. Bruschi, P. Sompornpisut and P. Turano, Proc. Natl. Acad. Sci. USA, 1996, 93, 14396-14400.

44 M. Czjzek, P. Arnoux, R. Haser and W. Shepard, Acta Crystallogr., Sect. D, 2001, 57, 670-678.

45 E. Afkar and Y. Fukumori, FEMS Microbiol. Lett., 1999, 175, 205 210.

46 J. R. Lloyd, E. L. Blunt-Harris and D. R. Lovley, J. Bacteriol., 1999, 181, 7647-7649.

47 S. Gaspard, F. Vazquez and C. Holliger, Appl. Environ. Microbiol., 1998, 64, 3188-3194.

48 S. Seeliger, R. Cord-Ruwisch and B. Schink, J. Bacteriol., 1998, 180, 3686-3691.

49 P. R. Pokkuluri, Y. Y. Londer, N. E. C. Duke, W. C. Long and M. Schiffer, Biochemistry, 2004, 43, 849-859.
50 M. Assfalg, I. Bertini, M. Bruschi, C. Michel and P. Turano, Proc. Natl. Acad. Sci. USA, 2002, 99, 9750-9754.

51 N. Pfennig and H. Biebl, Arch. Microbiol., 1976, 110, 3-12.

52 M. Brugna, W. Nitschke, R. Toci, M. Bruschi and M. T. GiudiciOrticoni, J. Bacteriol., 1999, 181, 5505-5508.

53 J. R. Lloyd, C. Leang, A. L. Hodges Myerson, M. V. Coppi, S. Cuifo, B. Methe, S. J. Sandler and D. R. Lovley, Biochem. J., 2003, 369 153-161.

54 M. Pessanha, Y. Y. Londer, W. C. Long, J. Erickson, P. R. Pokkuluri, M. Schiffer and C. A. Salgueiro, Biochemistry, 2004, 43, 9909-9917.

55 P. R. Pokkuluri, Y. Y. Londer, N. E. C. Duke, J. Erickson, M. Pessanha, C. A. Salgueiro and M. Schiffer, Protein Sci., 2004, 13, 1684-1692.

56 Y. Y. Londer, P. R. Pokkuluri, J. Erickson, V. Orshonsky and M. Schiffer, Protein Expression Purif., 2005, 39, 254-260.

57 M. Czjzek, F. Payan, F. Guerlesquin, M. Bruschi and R. Haser, J. Mol. Biol., 1994, 243, 653-667.

58 J. Morais, P. Nuno Palma, C. Frazao, J. Caldeira, J. Le Gall, I. Moura, J. J. G. Moura and M. A. Carrondo, Biochemistry, 1995, 34, 12830-12841.

59 Y. Higuchi, M. Kusunoki, Y. Matsuura, N. Yasuoka and M. Kakudo, J. Mol. Biol., 1984, 172, 109-139.

60 P. M. Matias, C. Frazao, J. Morais, M Coll and M. A. Carrondo, J. Mol. Biol., 1993, 234, 680-699.

61 P. M. Matias, J. Morais, R. Coelho, M. A. Carrondo, K. Wilson, Z. Dauter and L. Sieker, Protein Sci., 1996, 5, 1342-1354.

62 M. Bruschi, M. Loutfi, P. Bianco and J. Haladjian, Biochem. Biophys. Res. Commun., 1984, 120, 384-389.

63 C. Aubert, G. Leroy, P. Bianco, E. Forest, M. Bruschi and A. Dolla, Biochem. Biophys. Res. Commun., 1998, 242, 213-218.

64 A. Dolla, L. Florens, P. Bianco, J. Haladjian, G. Voordouw, E. Forest, J. Wall, F. Guerlesquin and M. Bruschi, J. Biol. Chem., 1994, 269, 6340-6346.

65 J. F. Heidelberg, R. Seshadri, S. A. Haveman, C. L. Hemme, I. T. Paulsen, J. F. Kolonay, J. A. Eisen, N. Ward, B. Methé, L. M. Brinkac, S. C. Daugherty, R. T. DeBoy, R. J. Dodson, A. S. Durkin, R. Madupu, W. C. Nelson, S. A. Sullivan, D. Fouts, D. H. Haft, J. Selengut, J. D. Peterson, T. M. Davidsen, N. Zafar, L. Zhou, D. Radune, G. Dimitrov, M. Hance, K. Tran, H. Khouri, J. Gill, T. R. Utterback, T. V. Feldblyum, J. D. Wall, G. Voordouw and C. M. Fraser, Nat. Biotechnol., 2004, 22, 554-559.

66 M. Bruschi, Methods Enzymol., 1994, 243, 140-155.

67 M. Czjzek, F. Guerlesquin, M. Bruschi and R. Haser, Structure, 1996, 4, 395-404.

68 C. Aubert, M. T. Giudici-Orticoni, M. Czjzek, R. Haser, M. Bruschi and A. Dolla, Biochemistry, 1998, 37, 2120-2130.

69 C. Frazão, L. Sieker, G. Sheldrick, V. Lamzin, J. LeGall and M. A. Carrondo, J. Biol. Inorg. Chem., 1999, 4, 162-165.

70 P. M. Matias, R. Coelho, I.A. C. Pereira, A. V. Coelho, A. W. Thompson, L. C. Le Gall, J. Sieker and M. A. Carrondo, Structure, 1999, 7, 119-130.

71 P. M. Matias, L. M. Saraiva, C. M. Soares, A. V. Coelho, J. Legall and M. A. Carrondo, J. Biol. Inorg. Chem., 1999, 4, 478-494.

72 I. Bento, V. H. Teixeira, A. M. Baptista, C. M. Soares, P. M. Matias and M. A. Carrondo, J. Biol. Chem., 2003, 278, 36455-36469.

73 L. M. da Costa, P. N. Saraiva, C. Conte, A. V. Xavier and J. LeGall, Biochim. Biophys. Acta, 2001, 1520, 63-70.

74 G. Fritz, D. Griesshaber, O. Seth and P. M. H. Kroneck, Biochemistry, 2001, 40, 1317-1324.

75 M. Czjzek, L. ElAntak, V. Zamboni, X. Morelli, A. Dolla, F. Guerlesquin and M. Bruschi, Structure, 2002, 10, 1677-1686.

76 P. M. Matias, A. V. Coelho, F. M. A. Valente, D. Plácido, J. LeGall, A. V. Xavier, I. A. C. Pereira and M. A. Carrondo, J. Biol. Chem., 2002, 277, 47907-47916.

77 T. Santos-Silva, J. M. Dias, G. Bourenkov, H. Bartunik, I. Moura and M. J. Romao, Acta Crystallogr., Sect. D, 2004, 50, 968-970.

78 I. A. C. Pereira, J. LeGall, A. V. Xavier and M. Teixeira, J. Biol. Inorg. Chem., 1997, 2, 23-31.

79 D. Leys, T. E. Meyer, A. S. Tsapin, K. H. Nealson, M. A. Cusanovich and J. J. Van Beeumen, J. Biol. Chem., 2002, 277, 35703-35711.

80 R. M. Esnouf, J. Mol. Graphics, 1997, 15, 132.

81 E. A. Merritt and D. J. Bacon, Methods Enzymol., 1997, 277, 505. 